\section{Blood shortage in COVID-19: A crisis within a crisis}

To the Editor: The coronavirus pandemic has had a devastating impact on healthcare resources in South Africa (SA) and the world at large. ${ }^{[1]}$ Donor blood supplies are not exempt, with national blood banks reporting critical depletions. This is a chronic, multifaceted issue that SA has had to face long before the onset of the pandemic, as fewer than $1 \%$ of citizens are active blood donors. ${ }^{[2]}$

Concerns had already been expressed by the South African National Blood Services (SANBS) prior to lockdown, as mentioned in early March 2020 by the SANBS chief marketing officer Silungile Mlambo, who stated that blood stocks were already declining. ${ }^{[3]}$ This deficit has been further exacerbated by the implementation of strict lockdown measures, effectively cutting down daily blood collections by more than $60 \% \cdot{ }^{[4]}$ Fortunately, a decrease in demand owing to cancellation of elective surgical procedures, a reduction in occurrence of trauma, and decreases in non-emergency medical treatment provided some compensation. However, compounding factors such as loss of crucial access to corporate blood drives at schools, universities and businesses ${ }^{[5]}$ have upset the balance once more. At the time of writing (21 December 2020) the shortage of blood products was expected to have disastrous implications during the festive season, when incidences of trauma and travel-related accidents generally soar. Our country has a significantly high burden of trauma, ${ }^{[6]}$ so it is of no surprise that this issue has reared its head yet again.

The two providers of this essential service, SANBS (which caters for eight of the nine provinces) and the Western Cape Blood Service (WCBS), have both reported shortages of the O blood group, a type of blood that can be universally transfused to all blood groups. ${ }^{[2]}$ At any given time, national blood banks are required to have a minimum blood supply for 5 days. ${ }^{[7]}$ However, at the time of writing, the SANBS reported that its blood reserves were deemed to last the better part of 3.5 days, with a platelet reserve that was expected to last 0.4 days. $^{[2]}$

The healthcare system is almost bursting at the seams owing to the demanding pressures of resource allocation and record-breaking patient influx. Additionally, with such critically depleted blood reserves, there is no doubt that challenging ethical dilemmas lie ahead for healthcare practitioners regarding allocation of healthcare resources.

At the time of writing it was estimated that 3174 lives were at immediate risk as a result of the shortage of blood products. ${ }^{[2]}$ Despite pleas for people to donate blood during the lockdown, ${ }^{[8]}$ blood supplies continue to be alarmingly low. ${ }^{[2]}$

The SANBS and WCBS are now urgently appealing to the public to visit their nearest mobile and fixed donor centres to review their donation eligibility in order to donate a unit of blood. Furthermore, any person who is willing to host a blood drive that adheres to COVID-19 social distancing and sanitisation protocols is urged to visit the SANBS or WCBS websites for more information. Such efforts are pivotal at this time, to prevent one devastating crisis from turning into another.

\section{T D Malange, T Atia}

Student interns, Faculty of Medicine and Health Sciences, Stellenbosch University, Cape Town, South Africa

19772572@sun.ac.za and 20119488@sun.ac.za

\footnotetext{
1. International Labour Organization. COVID-19 and the health sector. 26 June 2020. https://www.ilo.org sector/Resources/publications/WCMS_741655/lang--en/index.htm (accessed 21 December 2020). SANBS. Home page. https://sanbs.org.za/ (accessed 21 December 2020).

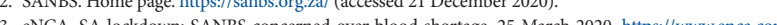
news/sa-lockdown-sanbs-concerned-over-blood-shortage (accessed 21 December 2020).

news/sa-lockdown-sanbs-concerned-over-blood-shortage (accessed 21 December 2020). Molelekwa T. Blood shortage fears as lockdown continues. Health-e News, 22 May 2020. https://he
org.za/2020/05/22/blood-shortage-fears-as-lockdown-continues/ (accessed 21 December 2020).

5. Molelekwa T. South Africa faces critical blood shortage on the eve of holiday travel. Health-e News 3 December 2020. https://health-e.org.za/2020/12/03/south-africa-faces-critical-blood-shortages-onthe-eve-of-holiday-travel/ (accessed 21 December 2020).

6. Zaidi AA, Dixon J, Lupez K, et al. The burden of trauma at a district hospital in the Western Cape Province of South Africa. Afr J Emerg Med 2019;9(Suppl):S14-S20. https://doi.org/10.1016/j.afjem.2019.01.007 Wise R, Gibbs M, Louw V. Lockdown and our national supply of blood products. S Afr Med 2020;110(5):337. https://doi.org/10.7196/SAMJ.2020.v110i5.14749

8. Business Insider South Africa. Please keep donating blood during lockdown, say blood services - here's where and how you can. 26 March 2020. https://www.businessinsider.co.za/blood-services-running-lowplease-donate-over-coronavirus-lockdown-2020-3_(accessed 21 December 2020).
}

S Afr Med J 2021;111(3):191. https://doi.org/10.7196/SAMJ.2021.v111i3.15525 